\title{
Weldability of HAYNES 282 superalloy after long-term thermal exposure
}

\author{
Jeremy Caron ${ }^{\mathrm{a}}$ and Lee Pike \\ Haynes International, Inc., Kokomo, Indiana, USA
}

\begin{abstract}
HAYNES $\AA 282 \AA$ alloy is a wrought gamma-prime $\left(\gamma^{\prime}\right)$ strengthened Ni-base superalloy that was developed for high-temperature structural applications, especially those in aero- and land-based gas turbine engines. The 282 alloy exhibits excellent creep strength and thermal stability in the 649 to $927^{\circ} \mathrm{C}$ temperature range, and was specifically designed for improved fabricability relative to other Ni-base superalloys. When welded in the annealed condition, 282 alloy exhibits excellent weldability for a $\gamma$ '-strengthened alloy. To provide an estimate of its weldability and weld repairability after service exposure, welding experiments were conducted on 282 alloy after long-term thermal exposure (LTTE). Welds were successfully completed on the LTTE material and transverse weld tensile properties were determined. To evaluate susceptibility to heat-affected zone (HAZ) liquation cracking during welding, Gleeble $\Omega$ hot-ductility tests were performed on the LTTE material. The experimental results were complemented by microstructure characterization and thermodynamic calculations. The capability of weld repair and rejuvenation of 282 alloy components in the LTTE condition was demonstrated.
\end{abstract}

\section{Introduction}

HAYNES 282 alloy (UNS N07208) is a wrought $\gamma^{\prime}-$ strengthened Ni-base superalloy developed for hightemperature structural applications, mainly in aero- and land-based gas turbine engines. 282 alloy has excellent creep strength in the temperature range of 649 to $927^{\circ} \mathrm{C}$, surpassing that of Waspaloy (UNS N07001) and similar to that of R-41 (UNS N07041) alloy. This level of creep strength was achieved with a significantly lower volume fraction of the strengthening $\gamma^{\prime}$ phase compared to R-41 alloy $[1,2]$.

The nominal chemical composition of 282 alloy is provided in Table 1. Its properties are developed through a two-step age-hardening heat treatment consisting of $1010^{\circ} \mathrm{C} / 2 \mathrm{hr} / \mathrm{AC}+788^{\circ} \mathrm{C} / 8 \mathrm{hr} / \mathrm{AC}$. The first step at a higher temperature results in the grain boundary precipitation of $\mathrm{Cr}$-rich $\mathrm{M}_{23} \mathrm{C}_{6}$ carbides. The second step of the heat treatment results in the formation of gammaprime $\left(\gamma^{\prime}\right)$ precipitates, which are spherical with an average diameter of approximately $20 \mathrm{~nm}$.

282 alloy is normally welded in the annealed condition and subjected to the age-hardening heat treatment after welding. When welded in the annealed condition, 282 alloy generally exhibits excellent weldability for a $\gamma$ '-strengthened alloy, including good resistance to strainage cracking $[3,4]$. However, little is known about the weldability of 282 alloy after service exposure, which, for example, would be required during weld repair.

${ }^{a}$ Corresponding author: jcaron@haynesintl.com HAYNES and 282 are registered trademarks of Haynes International, Inc.
This includes situations where a solution anneal prior to welding would be prohibitive. A full solution anneal after welding and prior to age hardening is normally suggested, but is not required in order to develop suitable properties. This study aimed to demonstrate the weld repairability and rejuvenation of 282 alloy components after service exposure.

\section{Experimental procedure}

Solution-annealed (SA) 282 plate of $27.0 \mathrm{~mm}$ thickness was age hardened according to the standard twostep heat treatment for 282 alloy: $1010^{\circ} \mathrm{C} / 2 \mathrm{hr} / \mathrm{AC}+$ $788^{\circ} \mathrm{C} / 8 \mathrm{hr} / \mathrm{AC}$. The aged material was then subjected to long-term thermal exposure (LTTE) at $760^{\circ} \mathrm{C}$ for 4000 hours. After the LTTE, the plate material was rapidly air cooled.

The LTTE material was subsequently gas metal arc welded (GMAW) with 282 weld filler metal after first installing a gas tungsten arc weld (GTAW) root pass. Transverse weld tensile tests were then performed at $20^{\circ} \mathrm{C}$ room temperature (RT), $760^{\circ} \mathrm{C}$, and $871^{\circ} \mathrm{C}$ in both the aswelded and postweld heat treated $1149^{\circ} \mathrm{C} / 30 \mathrm{~min} / \mathrm{WQ}+$ $1010^{\circ} \mathrm{C} / 2 \mathrm{hr} / \mathrm{AC}+788^{\circ} \mathrm{C} / 8 \mathrm{hr} / \mathrm{AC}$ conditions.

Additionally, hot-ductility tests were conducted on the LTTE material to evaluate susceptibility to weld heataffected zone (HAZ) liquation cracking. These tests were performed with a Gleeble $\AA 1500$ thermal-mechanical simulator. $6 \mathrm{~mm}$ diameter samples with threaded ends were machined from the LTTE plate material. On-heating tests were conducted by heating to the test temperature at $111^{\circ} \mathrm{C} / \mathrm{s}$, holding at temperature for $2 \mathrm{~s}$, and pulling to failure at $76.2 \mathrm{~mm} / \mathrm{s}$. On-cooling tests were conducted

This is an Open Access article distributed under the terms of the Creative Commons Attribution License 4.0, which permits unrestricted use, distribution, and reproduction in any medium, provided the original work is properly cited. 
Table 1. Nominal chemical composition of 282 alloy (Wt.\%).

\begin{tabular}{|c|c|c|c|c|c|}
\hline $\mathrm{Ni}$ & $\mathrm{Cr}$ & $\mathrm{Co}$ & $\mathrm{Mo}$ & $\mathrm{Ti}$ & $\mathrm{Al}$ \\
\hline $57^{* *}$ & 20 & 10 & 8.5 & 2.1 & 1.5 \\
\hline $\mathrm{C}$ & $\mathrm{B}$ & $\mathrm{Fe}$ & $\mathrm{Mn}$ & $\mathrm{Si}$ & \\
\hline 0.06 & 0.005 & $1.5^{*}$ & $0.3^{*}$ & $0.15^{*}$ & \\
\hline
\end{tabular}

*Maximum, **As Balance.

by heating to $1204^{\circ} \mathrm{C}$ at $111^{\circ} \mathrm{C} / \mathrm{s}$, holding for $2 \mathrm{~s}$, and free cooling to the test temperature, holding for $2 \mathrm{~s}$, and then pulling to failure at $76.2 \mathrm{~mm} / \mathrm{s}$. Following testing, the diameter of the fracture surfaces were measured and compared to the original diameter to determine the percent reduction-in-area (\%RA).

After testing, samples were submitted for metallographic analysis. After mounting and polishing, electrolytic etching was performed in a solution consisting of $5 \mathrm{~g}$ oxalic acid $\left(\mathrm{H}_{2} \mathrm{C}_{2} \mathrm{O}_{4}\right)$ mixed with $95 \mathrm{ml}$ reagent grade hydrochloric acid $(\mathrm{HCl})$. To reveal the $\gamma^{\prime}$ precipitates for scanning electron microscopy (SEM), samples were electrolytically etched with chromic acid $\left(\mathrm{H}_{2} \mathrm{CrO}_{4}\right)$ made from $15 \mathrm{~g}$ of crystalline chromium oxide $\left(\mathrm{CrO}_{3}\right)$, plus $10 \mathrm{~mL}$ of concentrated sulfuric acid $\left(\mathrm{H}_{2} \mathrm{SO}_{4}\right)$ dissolved in $150 \mathrm{~mL}$ of $85 \%$ phosphoric acid $\left(\mathrm{H}_{3} \mathrm{PO}_{4}\right)$ [5]. The etchant also reveals the presence of $\gamma^{\prime}$ as a dark tint when examined in the light optical microscope.

\section{Results and discussion}

\subsection{LTTE microstructure}

SEM micrographs of 282 alloy in the LTTE condition are shown in Fig. 1. In addition to intergranular $\mathrm{Cr}$-rich $\mathrm{M}_{23} \mathrm{C}_{6}$ carbides, intra-and inter-granular Mo-rich $\mathrm{M}_{6} \mathrm{C}$ carbides were present. Also visible are spherical $\gamma^{\prime}$ particles with an average diameter of approximately $100 \mathrm{~nm}$. Particle diameters as large as $175 \mathrm{~nm}$ were observed. The increased size of the $\gamma^{\prime}$ particles compared to an average of $20 \mathrm{~nm}$ typically found in fully age-hardened material indicates that significant coarsening had occurred during the thermal exposure. Large primary $\mathrm{Ti}(\mathrm{C}, \mathrm{N})$ and (Ti,Mo)-rich $\mathrm{MC}$ particles were also present in the microstructure, which remained from original ingot solidification. These phases are in good agreement with those previously identified for LTTE of 282 alloy at $760{ }^{\circ} \mathrm{C}$ [6].

Thermodynamic calculations with the Thermotech Nibased Superalloys Database v8.0 (TTNi8) indicate the stable phases at $760^{\circ} \mathrm{C}$ to be $\gamma, \gamma^{\prime}, \mathrm{M}_{23} \mathrm{C}_{6}$, and $\mathrm{M}_{3} \mathrm{~B}_{2}$. These phases were all observed in the microstructure with the exception of $\mathrm{M}_{3} \mathrm{~B}_{2}$, which is a Mo-rich boride that is difficult to detect, but is likely present in small amounts at the grain boundaries. It is expected that the primary $\mathrm{MC}$ carbides in the $\gamma$ matrix begin transformation to $\gamma^{\prime}$ and $\mathrm{M}_{23} \mathrm{C}_{6}$ upon prolonged exposure to $760{ }^{\circ} \mathrm{C}$. Within the nominal composition range of 282 alloy, topologically closed packed (TCP) phases such as $\mu$ and $\sigma$ are also predicted to form at $760{ }^{\circ} \mathrm{C}$; however, there was no experimental evidence of their presence in this investigation. More detailed characterization is ongoing and will be published elsewhere.
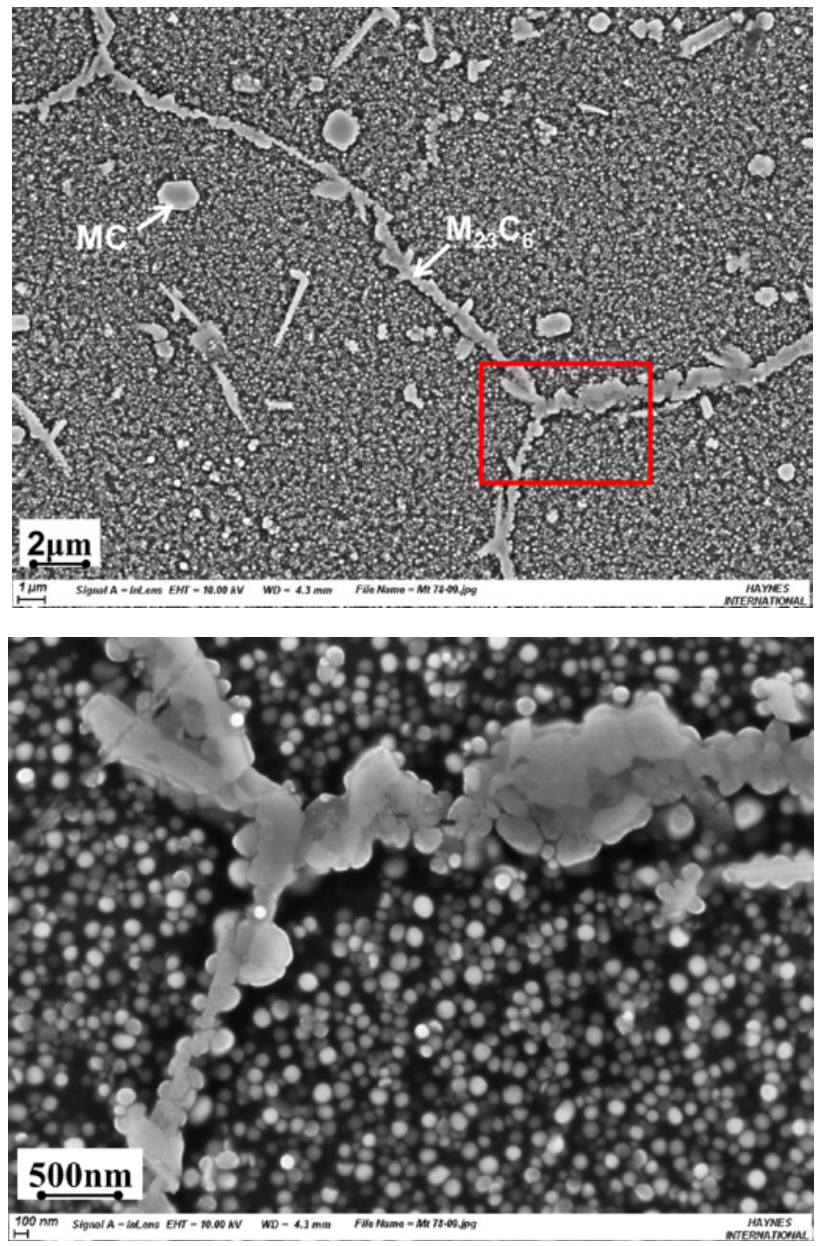

Figure 1. SEM micrographs of 282 alloy in the LTTE condition. Location of bottom micrograph indicated in top micrograph.

\subsection{Welding experiments}

Shown in Fig. 2 is an optical micrograph of a LTTE weldment etched to reveal the presence of $\gamma^{\prime}$. The weldment shown is from $3.2 \mathrm{~mm}$ sheet that was welded in a similar LTTE condition. The micrograph exhibits a lack of etchant tint in the HAZ closest to the weld metal (WM). This indirect evidence of $\gamma^{\prime}$ dissolution was confirmed by SEM characterization. Since the region closest to the weld experiences a peak temperature approaching the nominal liquidus of 282 alloy $\left(\approx 1375^{\circ} \mathrm{C}\right)$, it reasons that there would be dissolution of the $\gamma^{\prime}$ phase at temperatures well above its solvus of $\approx 1000^{\circ} \mathrm{C}$.

There was evidence of liquation in the partially melted zone (Fig. 2), which is the location of the HAZ adjacent to the weld metal. This was apparent by widened grain boundaries that were absent of carbides and "halo" features existing around larger carbides that had only partially liquated. Liquation also coincided with regions of the LTTE microstructure containing a higher density of carbides. It is typical for highly alloyed Ni-base alloys to exhibit liquation in this region of the HAZ. However, there was no evidence of liquation cracking in the HAZ. In the presence of grain boundary liquation, cracks would be more likely to form under higher weld restraint conditions. 

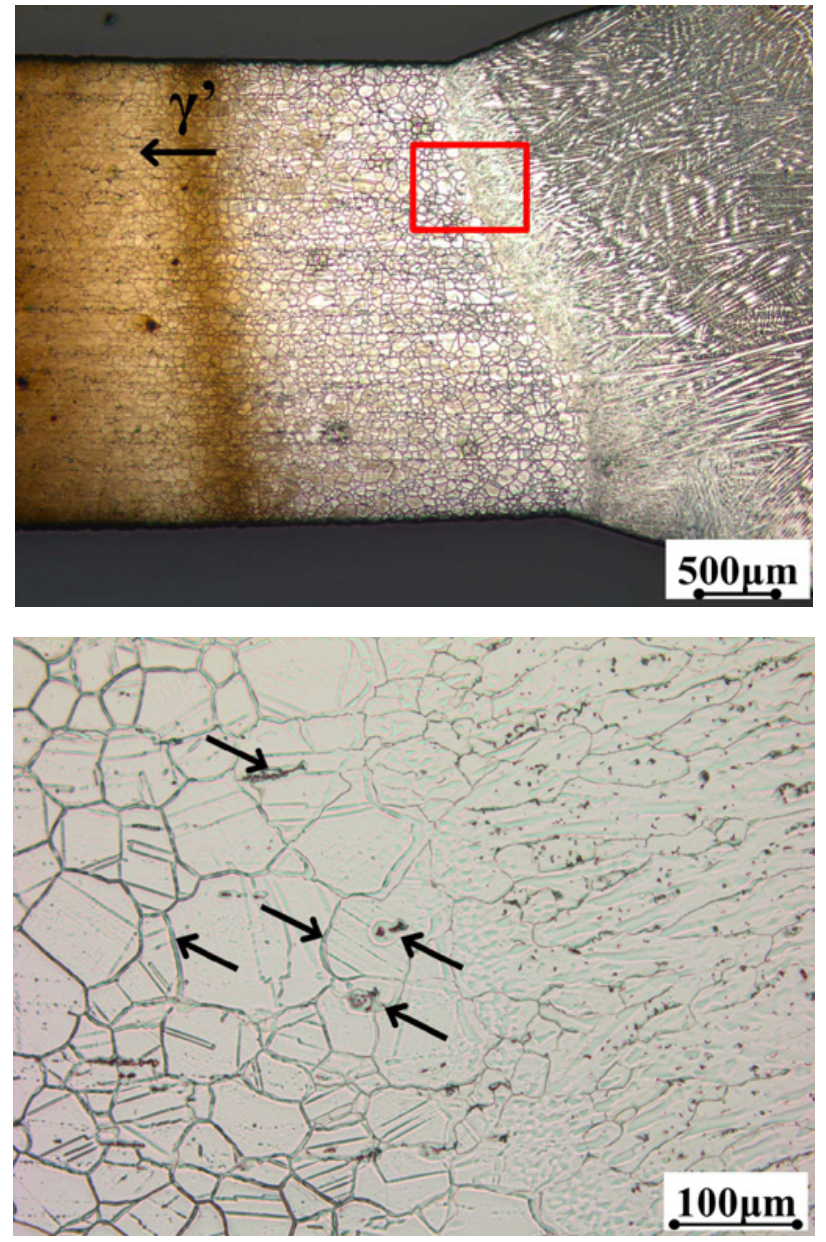

Figure 2. Optical micrographs of LTTE 282 weldment in aswelded condition. Location of bottom micrograph indicated in top micrograph. HAZ liquation noted by arrows in bottom micrograph.

SEM analysis of the HAZ revealed that the primary $\mathrm{MC}$ and $\mathrm{Ti}(\mathrm{C}, \mathrm{N})$ particles remained stable at the highest temperatures, as well as a majority of the Mo-rich carbides. However, there was no evidence of $\mathrm{Cr}$-rich carbides in the partially melted zone, which suggests their contribution to the observed HAZ liquation.

For microstructures examined after postweld heat treatment, Cr-rich carbides, presumably $\mathrm{M}_{23} \mathrm{C}_{6}$, were observed along grain boundaries, primary (Ti,Mo)-rich MC carbides in the $\gamma$ matrix, and fine $\gamma$ ' precipitates (Fig. 3) with a size similar to that typically observed in age-hardened material. The $\gamma^{\prime}$ precipitates were found throughout the $\gamma$ matrix and at the grain boundaries in both the base metal (BM) and weld metal (WM). Average particle size was seen to increase nearer to the grain boundary; slightly larger particles were observed in the BM. $\gamma$ ' precipitation that extends to the grain boundaries in the WM is considered a positive feature of 282 alloy since $\gamma^{\prime}$-free zones near grain boundaries would have a negative effect on creep strength. It could be concluded that the LTTE 282 microstructure had been rejuvenated upon postweld solution annealing and age hardening with respect to the formation of its two key secondary phases.
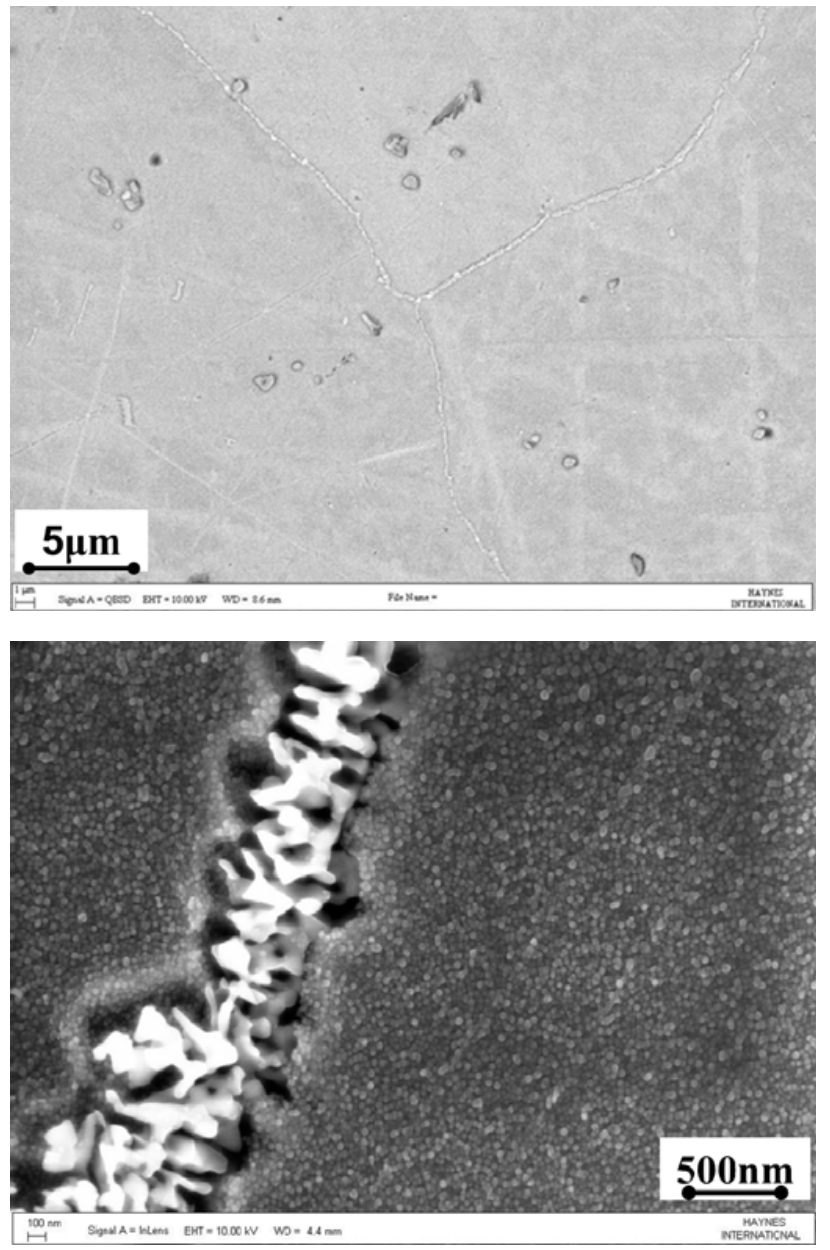

Figure 3. SEM micrographs of LTTE 282 weldment in BM after postweld heat treatment. Fine $\gamma^{\prime}$ precipitates are shown in the lower micrograph. Note that grain boundary carbides were removed by the $\gamma^{\prime}$ etchant.

\subsection{Transverse weld tensile tests}

The transverse weld tensile results for the LTTE 282 weldment are provided in Table 2 . The $20^{\circ} \mathrm{C}$ data represents a single test, while the elevated temperature data are an average from duplicate tests. Ductility values are provided for information only since they are highly dependent on fracture location. The as-welded samples tested at $760{ }^{\circ} \mathrm{C}$ exhibited the lowest ductility values as a result of failing in the weld metal (WM). The two aswelded samples tested at $871{ }^{\circ} \mathrm{C}$ fractured in different locations. One of the samples failed in the WM and the other failed in the BM/HAZ. The measured ductility of the sample that failed in the WM was significantly lower than for the sample that failed in the BM/HAZ. This result is due to strain localization that occurred in the WM during the transverse weld tensile test, which decreases the percent elongation by effectively shrinking the gage length. However, the $0.2 \% \mathrm{YS}$, and more importantly, the UTS of the two samples were found to be almost equivalent. While this finding does indicate that the various regions of the LTTE weldment had relatively consistent strength in the as-welded condition, there was 
Table 2. Transverse weld tensile results of 282 alloy welded in the LTTE condition.

\begin{tabular}{|c|c|c|c|c|c|}
\hline $\begin{array}{l}\text { Test } \\
\text { Temp } \\
\left({ }^{\circ} \mathrm{C}\right)\end{array}$ & $\begin{array}{l}0.2 \% \\
\text { YS } \\
\text { (MPa) }\end{array}$ & $\begin{array}{l}\text { UTS } \\
\text { (MPa) }\end{array}$ & $\begin{array}{l}\text { Elon } \\
(\%)\end{array}$ & $\begin{array}{l}\text { RA } \\
(\%)\end{array}$ & $\begin{array}{l}\text { Fracture } \\
\text { Location }\end{array}$ \\
\hline \multicolumn{6}{|c|}{ GMAW As-Welded } \\
\hline 20 & 643 & 928 & 17.3 & 45.1 & WM \\
\hline 760 & 631 & 764 & 5.9 & 21.6 & WM \\
\hline 871 & $\begin{array}{l}354 \\
360\end{array}$ & $\begin{array}{l}496 \\
503\end{array}$ & $\begin{array}{l}7.8 \\
26.9\end{array}$ & $\begin{array}{l}9.7 \\
60.8\end{array}$ & $\begin{array}{l}\text { WM } \\
\text { BM/HAZ }\end{array}$ \\
\hline \multicolumn{6}{|c|}{$\begin{array}{l}\text { GMAW }+ \\
11499^{\circ} \mathrm{C} / 30 \mathrm{~min} / \mathrm{WQ} \\
\mathbf{7 8 8}^{\circ} \mathrm{C} / \mathbf{8 h r} / \mathrm{AC}\end{array}$} \\
\hline 20 & 648 & 945 & 13.7 & 15.7 & BM/HAZ \\
\hline 760 & 561 & 780 & 13.2 & 17.2 & $\mathrm{BM} / \mathrm{HAZ}$ \\
\hline 871 & 483 & 561 & 16.6 & 17.4 & BM/HAZ \\
\hline
\end{tabular}

clearly lower ductility in the WM at elevated temperatures compared to RT values.

For postweld heat treated samples, tensile failure consistently occurred in the BM. This suggests that the $282 \mathrm{WM}$ had higher strength compared to the BM/HAZ following the postweld heat treatment, which is consistent with transverse weld tensile test results of 282 plate welds in the postweld age-hardened condition. In fact, the $0.2 \%$ YS of 282 all-weld-metal samples in the agehardened condition and 282 plate samples in the agehardened condition is typically equivalent at RT and elevated temperatures; this is considered to be a positive feature of 282 alloy. As such, transverse weld tensile samples of 282 plate weldments typically fail in the softened BM/HAZ region, which is viewed favourably from a weldability standpoint. Compared to the as-welded condition, the overall tensile properties were improved after postweld heat treatment. While re-solutionizing and age hardening is not considered necessary, it may be beneficial to overall tensile properties.

The RT tensile strengths for the postweld heat treated samples were compared to tensile data previously generated for 282 alloy [7] (Fig. 4). Transverse weld (T-Weld) tensile samples in the postweld age-hardened condition typically exhibit a small debit in RT $0.2 \%$ YS and UTS compared to solution annealed plate that is subsequently age-hardened (SA/Age). When compared to these data, the LTTE welded samples in a similar postweld age-hardened condition exhibited a similar debit in $0.2 \% \mathrm{YS}$ and a larger debit in UTS. This could be partially attributed to a relatively large grain size in the $\mathrm{BM} / \mathrm{HAZ}$ where fracture occurred. The average grain size in the fracture region had increased to ASTM No. 1.5-1.0, which corresponds to an average grain diameter of 213.6$254.0 \mu \mathrm{m}$. Grains as large as ASTM No. $0(359.2 \mu \mathrm{m})$ were observed. This compares to the ASTM No. 4.0 $(89.8 \mu \mathrm{m})$ typically observed in mill-annealed 282 alloy. The large grain size would have resulted from both the HAZ thermal cycle and a slightly higher postweld solution annealing temperature of $1149^{\circ} \mathrm{C}$ for the LTTE welded samples compared to the typical $1135^{\circ} \mathrm{C}$ SA temperature. Since 282 alloy is primarily used in applications requiring

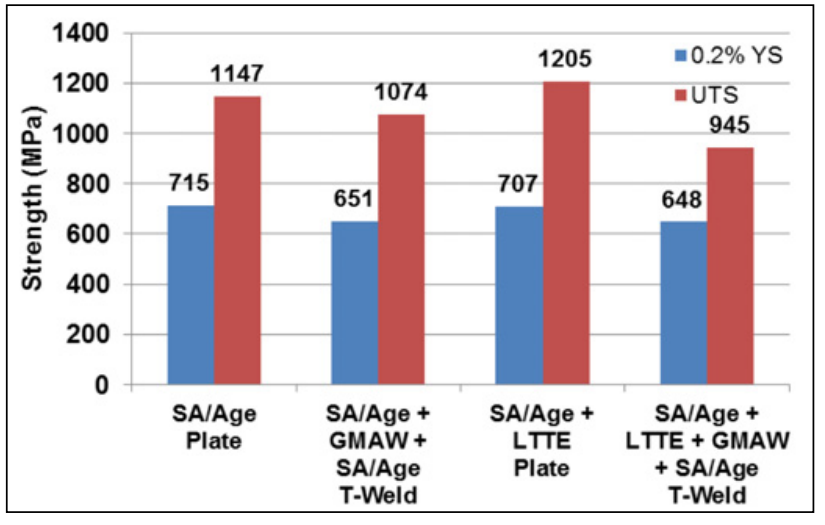

Figure 4. RT strength values of 282 alloy in different conditions.

good creep strength, the tensile properties may be of less significance; however, they act to illustrate the observed microstructural differences.

\subsection{Hot-ductility tests}

Shown in Fig. 5 are the \%RA measured for on-heating and on-cooling hot-ductility test samples of 282 plate in the LTTE condition. Several on-heating and on-cooling tests were performed in order to determine susceptibility to HAZ liquation cracking in the LTTE condition. As can be seen in Fig. 5, on-heating and on-cooling ductility values are very similar for a given test temperature. For on-heating data, there is a steep decrease in ductility that occurs just below the nil-ductility temperature (NDT) of $\approx 1175^{\circ} \mathrm{C}$. This steep decrease is typical on-heating behaviour for Ni-base alloys and represents the onset of melting within the microstructure, usually in the form of grain boundary liquid films [8].

Upon heating to a peak temperature of $1204{ }^{\circ} \mathrm{C}$ and cooling to selected test temperatures, the on-cooling ductility was shown to recover to similar values obtained for on-heating tests. For example, at $1149^{\circ} \mathrm{C}, 29 \%$ RA was achieved in the on-cooling test compared to $18.5 \% \mathrm{RA}$ in the on-heating test. This immediate recovery in ductility is viewed favourably in terms of HAZ liquation cracking resistance. Upon further cooling from the peak temperature, a maximum of $72 \% \mathrm{RA}$ was achieved at a test temperature of $1093^{\circ} \mathrm{C}$ before levelling off at $\approx 50 \% \mathrm{RA}$ at lower temperatures.

The microstructure near the fracture surface of the NDT sample is shown in Fig. 6. Liquated regions were observed mainly along grain boundaries. Evidence of liquation near the fracture surface was most predominant in regions with a high carbide density. Since $\gamma^{\prime}$ dissolution was observed much further from the fracture surface, it is not expected to have contributed to the observed liquation mechanism. As shown in Fig. 7, the darker etched region represents the presence of $\gamma^{\prime}$ precipitates, whereas the region closer to the fracture surface indicates that $\gamma^{\prime}$ is not present in the microstructure due to dissolution at higher temperatures. The peak temperature in the region of the sample where $\gamma$ ' did not dissolve would have been lower 


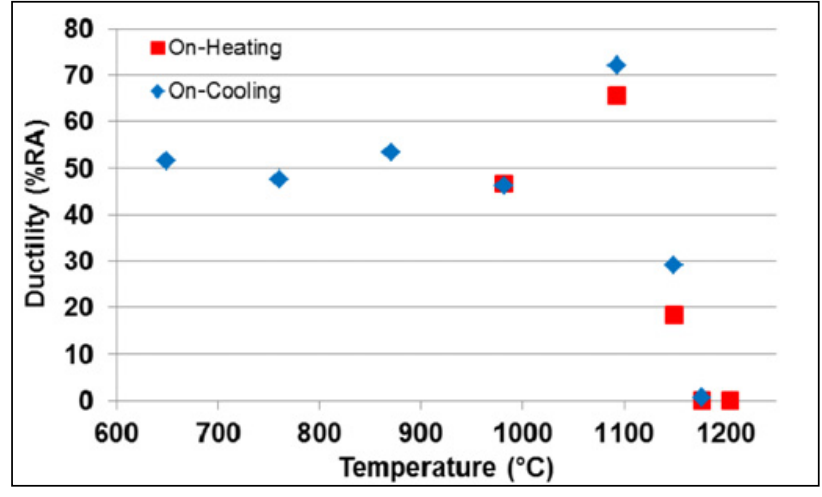

Figure 5. Measured hot-ductility values for 282 alloy in LTTE condition.

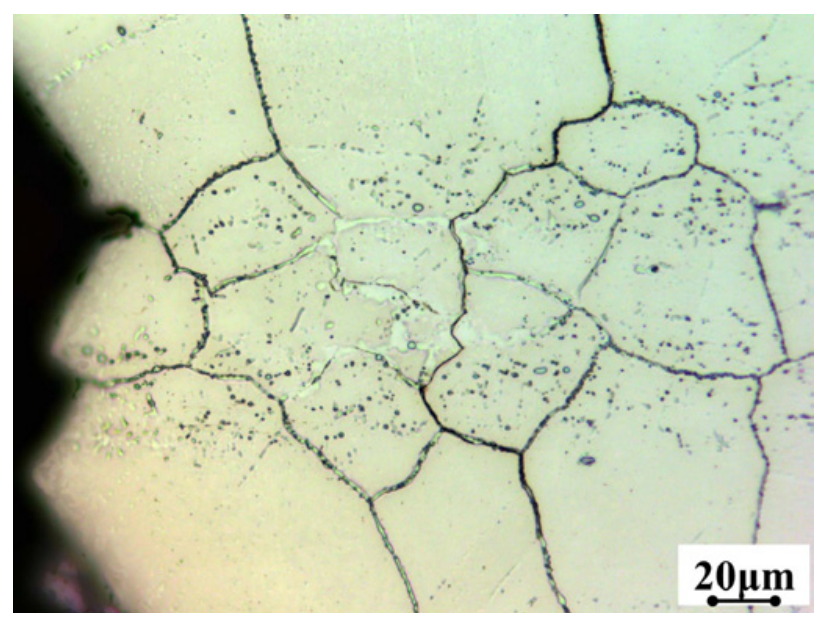

Figure 6. Optical micrograph of 282 NDT sample exhibiting evidence of liquation near the fracture surface.

than at the middle of the sample where fracture occurred $\left(1204^{\circ} \mathrm{C}\right)$ due to the thermal gradient along the length of the sample. The interface between the presence and absence of $\gamma^{\prime}$ establishes the temperature in that region of the sample to be at least $\approx 1000{ }^{\circ} \mathrm{C}$, the measured $\gamma^{\prime}$ solvus.

Based on microstructural evidence, liquation in onheating samples is primarily attributed to the liquation of the Cr-rich $\mathrm{M}_{23} \mathrm{C}_{6}$ carbides. Liquation was also likely exacerbated by the presence of boron at the grain boundaries, which is known to enhance wetting. This liquation mechanism is similar to that exhibited by 282 alloy in the age-hardened condition [9]. Thus, it can be concluded that the LTTE condition does not result in significantly different HAZ liquation cracking susceptibility compared to 282 alloy in the annealed or age-hardened conditions.

\section{Summary and conclusions}

1. In addition to large primary $\operatorname{Ti}(\mathrm{C}, \mathrm{N})$ and $(\mathrm{Ti}, \mathrm{Mo})$ rich MC particles, the microstructure of 282 in the LTTE condition exhibited mainly intergranular

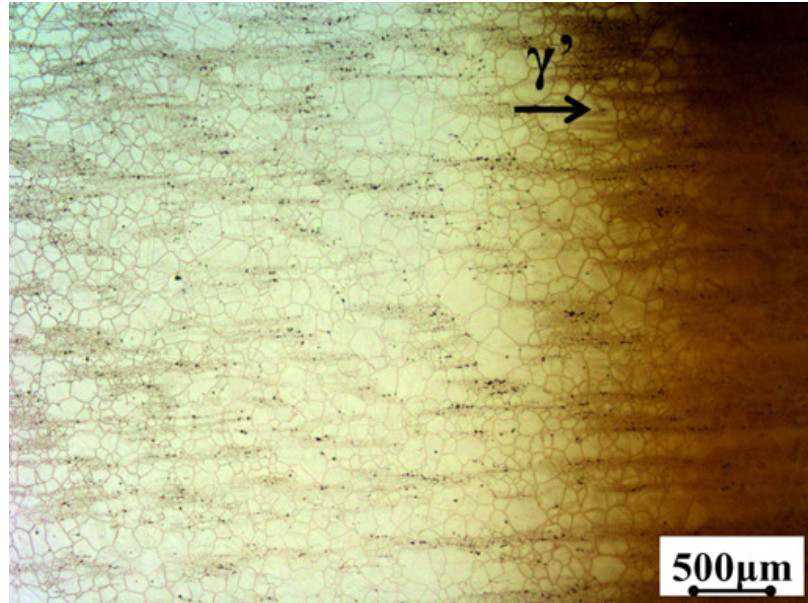

Figure 7. Optical micrograph of 282 NDT sample at a location well away from the fracture surface. The sample was etched to reveal the presence of $\gamma^{\prime}$ precipitates.

Cr-rich $\mathrm{M}_{23} \mathrm{C}_{6}$ carbides and intra-and inter-granular Mo-rich $\mathrm{M}_{6} \mathrm{C}$ carbides. $\gamma^{\prime}$ precipitates with an average diameter of approximately $100 \mathrm{~nm}$ were also visible.

2. The weldability of 282 alloy in the LTTE condition was demonstrated. Welds were successfully completed without cracking or other weld defects. This suggests that a pre-weld solution anneal is not necessary prior to repair welding 282 material that has been in service. There was evidence of liquation in the HAZ nearest to the WM, but no evidence of HAZ liquation cracking. With respect to the formation of the two key secondary phases, intergranular $\mathrm{M}_{23} \mathrm{C}_{6}$ and intragranular $\gamma^{\prime}$, the LTTE microstructure exhibited rejuvenation upon postweld solution annealing and age hardening.

3. The room and elevated temperature tensile properties of LTTE 282 weldments were determined. In the aswelded condition, failure generally occurred in the WM. At $871{ }^{\circ} \mathrm{C}$, strength was consistent regardless of the failure location. After postweld heat treatment, tensile failure consistently occurred in the BM/HAZ. Compared to other samples in a similar age-hardened condition, the LTTE welded samples exhibited lower strength, which was attributed to a relatively large HAZ grain size.

4. In on-cooling hot-ductility testing, 282 alloy exhibited excellent ductility recovery. Ductility values for on-cooling tests were similar to on-heating tests. This suggests that 282 alloy possesses excellent resistance to HAZ liquation cracking when welded in the LTTE condition.

\section{References}

[1] L. Pike, Proceedings of ASME Turbo Expo 2006, GT2006-91204, 1031 (2006)

[2] L. Pike, Superalloys 2008, 191 (2008) 
[3] D. Metzler, Weld. J., 87, 249-s (2008)

[4] D. Metzler, Weld. J., 91, 163-s (2012)

[5] J. Radavich, Superalloys 718, 625, 706 and Various Derivatives, 18 (1997)

[6] L. Pike, $7^{\text {th }}$ International Symposium on Superalloy 718 and Derivatives, 645 (2010)
[7] Haynes Intl. HAYNES $\AA 282 \AA$ alloy brochure, http://www.haynesintl.com/pdf/h3173.pdf (2008)

[8] J. DuPont, J. Lippold, S. Kiser, Welding Metallurgy and Weldability of Nickel-Base Alloys, 394 (2009)

[9] J. Caron, $8^{\text {th }}$ International Symposium on Superalloy 718 and Derivatives, accepted for publication (2014) 